\title{
The pedagogical concept of laboratory and videogames: learning by having fun
}

\author{
Tiziana Iaquinta $^{\text {a }}$ \\ ${ }^{a}$ Università Magna Graecia Catanzaro, Italy, iaquinta@unicz.it, https://orcid.org/0000-0002-0943-1275
}

\begin{abstract}
There are numerous pedagogues who look at new media with interest (Maragliano 2003; Rivoltella 2006;), paying attention also to the world of computer games and, particularly, to the so-called field of edutainment. The educational, cognitive and metacognitive implications of the sophisticated technology devices involved and their characteristics of creativity, socialisation, practicality and engagement, already recognised by experts in the field, qualify these devices to be considered interesting tools for playing and laboratory learning. They should be used to support the traditional didactic and educational activities in order to outline a new idea of laboratory and school.
\end{abstract}

Keywords: school laboratory, active learning, videogames, new technologies, learning

\section{Videogames and new technologies for playing and learning}

For some time now, studies in the field of education have been attributing certain validity to videogames as a support to both didactic activities and the process of learning (Greenfield, 1985; Herz, 1998). However, what has not been yet investigated is the possible link between videogames and Dewey's laboratory concept. This brief reflection focuses on the concept of a 'laboratory school', considering the possibility offered by multimedia instruments and new technologies, particularly previous-generation videogames, with the purpose not only of confirming the validity of Dewey's 'laboratory' theory on didactics and formation, which, even in the context of changing times, continues to be a current pedagogical concept and an innovative way of schooling (Dewey, 1992), but also to hypothesise a restatement considering the teaching-educational possibilities offered by computer games. The latest games, in their different types and themes, may represent the manual learning activities at the centre of active education in the new school laboratory. Considering this objective, it should be emphasised that there are numerous scholars in the field who recognise the undoubted validity of videogames as learning facilitators and motivators (Tanoni, 2003).

For quite some years now, in almost all the countries of the world, educators and teachers have begun using, with increasing frequency, videogames in the knowledge acquisition process. In October 2007, the OCDE at the Catholic University of Santiago in Chile highlights through its activities that today's youth, because they are not like their older brothers/sisters, prefer a different way of mastering knowledge, within which technology is omnipresent, including videogames On the other hand, traditional educational systems are not very enthusiastic in receiving this new student, who lives immersed in a technologised world full of incentives and opportunities, which leads him/her almost to 'disassociate' from where he lives and what surrounds him when at school. At school, during the various stages of education, the alternatives to traditional lessons are rare and weak. Learning takes place in accordance with established methods and does not take into account the fact that students are digital natives. Even if this definition may sound too simple, companies employing people such as videogame editors invest and win in what Sefton-Green has defined as the competition for engaging young people's heart and soul (Claro, 2007). In order to be in step with the transition towards a society of digital knowledge, traditional systems, therefore, should try to fill in the gap between school and real life (Huerre, 2008).

These considerations represent an important starting point for deepening the reflection on the importance and efficacy of videogames in a school environment and, in particular, an invitation to bridge the gap between school life and extracurricular life, to arouse greater interest in the student, because it recalls the thoughts of Dewey, specifically the pedagogical idea of continuity between school and family lives, here in a wider meaning, in order to better promote students' learning. We know well that knowledge is not developed through just one channel, but at different multiple levels. This is why in dealing with the types of knowledge linked to the use of videogames, we must not omit references 


\section{The pedagogical concept of laboratory and videogames: learning by having fun}

Iaquinta

to de Kerckhove's (1993) 'brainframes', Fodor's (2003) theory of the modular mind, and Gardner's (2005) theory of multiple intelligence.

With reference to new technologies, de Kerckhove claims that they have radically changed our 'brainframe'; in other words, the frames around our brain have different interpretation and communication models. Just like the 'brainframe' created by the alphabet has organised the way in which we organise our thoughts, in the same way, the 'brainframe' created by computers and videogames influences our elaboration of information and the perception of things. Fodor focuses attention on the fact that human knowledge is divided into a series of partial cognitive domains and modules, intended as peripheral systems whose task is to analyse the input that refers to sensorial-perceptual modality and language. The modules are represented as an orange, made up of slices, which are well separated among themselves.

In addition to these theories, Gardner's theory of 'multiple intelligence' gives us a theoretical picture that answers the question of how and whether different communication processes can influence cognitive processes.

According to Gardner, more than one type of innate intelligence exists in our brain: linguistic, musical, mathematical, logical, visual-spatial, bodily kinaesthetic and personal intelligence, and to a certain stimulus corresponds a certain type of human intelligence.

Gardner lists the general intelligence types of the human mind and claims that once the nature of human intelligence is specified, we should be capable of creating a list of all the possible symbol systems and, if we want, of all the fields in which human beings can commit intellectually. The list would be very long because the number of cultural roles is vast and can be continuously made longer with the invention of new technologies (Gardner, 2005). The videogame is, in fact, a new technology and it has a cultural role of great impact on the individual and stimulates all intelligence types mentioned by Gardner. Certain of the cultural role of videogames, we can deduce that they can develop competences, or intelligences, some strictly linked to the electronic game, others useful on a practical level.

A long time ago, pedagogical research started an interesting theoretical and methodological reflection on the reality of videogames. In particular, three areas of research that directly involve educational science can be highlighted: literacy towards media, effects of videogames and didactic videogames.

The first area of research concerns the study of innovative literacy scenarios in media, in other words, education through critical comprehension of media messages and images, in order to ensure that everyone has access to all types of media; investing in literacy through the media at the European, national and local levels; investing in literacy through the media - starting from the education of younger children through primary and secondary schools at all levels, not only with targeted media literacy classes but also through the provision of cross-education curriculum; encouraging media literacy within informal education; and so on.

In this view, media is seen as real life, language and culture, and the formation of multimedia competences starts early in kindergarten (Rivoltella, 2006)

The second area of pedagogical research refers to psychosocial studies (Boyd, 2014; Cacioppo and Severino, 2015) on the effects of mass media.

The third area of study is characterised by the study of videogames as tools of didactic innovation capable of fostering learning that is more effective.

For many years in fact, there has been an enormous variety of videogames on the market, which Melai and Bernardi (2003) tried and enclosed in three categories, as follows (Melai, 2003):

- Entertainment: games just for entertainment

- Edutainment: games with the purpose of learning

- Educational-didactic: multimedia products dedicated to learning

In addition to these, there are other more detailed classifications of videogames, such as, for instance, the one formulated by Roiazzi on the basis of players' tasks (Roiazzi, 2003).

Particularly, the term edutainment is derived from the fusion of education and entertainment, which means ludic learning; it indicates teaching products that combine games with education, proposing a strategy of learning that has been brought about by videogames and digital simulation. Therefore, videogames represent a new medium, which intends to be a funny educational tool and 'effortless' too, but no less demanding of the skills and abilities of the person, because the characteristics of the medium are interactivity, multimedia, multisensory perception and problem solving. Videogames, in fact, require a constantly active participation, made up of stimulus-response exchanges, choices, instant and/or delayed gratification, as well as problems whose resolution allows progress both in the game and in personal knowledge (Cecchelli, 2009). These features make computer games accessible within the school if placed within a teaching plan that can use them to build a learning process as much seductive and motivating for the student as in tune with his extracurricular interests and in line with the technological times in which they live. Dewey's conception of the laboratory may be the theoretical background to refer to for accommodating computer games at all school levels. On the other hand, Hickman, one of the greatest scholars of John Dewey, in a paper published a few years ago said that the American pragmatist philosopher would have been an enthusiastic supporter of Internet use in educational environments (Hickman, 2003, p. 55), albeit with caution and with the necessary attention (Hickman, 2003). According to Hickman, Dewey would have certainly appreciated the high level of participation that the Web produces, providing access to small and large problems every day and alternative ways of conceiving, as well as increased opportunities for teacher-student interaction (Hickman, 2003, p. 55). For these reasons and considering the possibility of learning offered by computer games, it is possible to envisage their use in a teaching laboratory and a new way of teaching. 


\section{Laboratory concept and videogames: brief reflections}

The concept of laboratory, which has been debated as part of the Italian pedagogy since the mid-twentieth century, is even today qualified as an innovative way 'to teach', to see and think of the relationship between teaching and learning, as well as an occasion to learn and exercise democracy of practice. Open-mindedness, flexibility, 'the practical feasibility of experience', the synergic participation of the individuals and social integration are some of the characteristics that make the laboratory context a democratic one (Dewey, 1989). However, today, it is necessary to think over and redefine the concept of laboratory considering the changes that the digital world and new media have introduced in society, in the habits of young people and, consequently, in their ways of learning.

The redefinition of the concept of laboratory, in fact, in the perspective of Dewey's proposal and Francesco De Bartolomeis' (1978) Italian interpretation, makes the enacting of the 'learning laboratory' possible, even if in a small part with respect to the original idea, which was the foundation for the Laboratory School in Chicago. This was the 'laboratory school' created and managed by Dewey. The school experience, described by the American philosopher and pedagogue in School and Society (Dewey, 1989), rose to the model of an active school by the efforts of the creators of the new activist school movement. Though it never found full application in school, even with the characterising aspects it is made up of, it is considered the herald of educational possibilities for the student, who is made capable of learning directly or indirectly not only the knowledge of the subjects, the know-how to do things, but also the knowledge that is derived from living in a new way of schooling, participating, sharing, researching, socialising, creating, producing, and so on. This becomes knowing how to live. Till date, we continue to refer to the concept of laboratory and 'laboratory school' when we talk about innovation within the school system and learning motivation for the student. The same can be said for schools with a laboratory structure, laboratory methods, laboratory didactics, and so on, but with a very different terminology, even if the laboratory actually remains concerned mostly with lexical variables instead of activating issues.

It is best to remember that the laboratory is the place in which a learning context is created; it is different compared to the traditional one, and the knowledge acquired through individual and group research, personal experience, active listening, motivated participation, creativity, discovery, production, interaction, practising experiences, and so on is achieved through procedures, instruments and suitable materials that foster a learning process in proportion to the student's educational level and his or her needs. In times like today's, dominated by new technologies, new media and social networks, the learning issue becomes even more urgent and complex (Iaquinta, 2005).

Pedagogy has to indicate some new ways of learning in the school. These ways of learning have to be in line with the students' multimedia needs. Students, equipped with increasingly sophisticated software, are greatly attracted by the possibilities of social interaction and the acquisition of knowledge related to technological devices.

Experimenting, digitizing and interacting - the modality of practical feasibility represents, for the young person, the 'handy' world, a world that is, at the same time, unlimited and delimited, handheld, 'contained' in a tablet or another attractive multimedia device, without which young people do not want to know, and neither know they how to do without, any more (Calvani, 2007). Therefore, it is opportune that digital natives also learn through some ways of acquisition of knowledge, which are in harmony with these new opportunities. This has to be provided in order to avoid dysfunctions between the knowledge offered by the school, which is perceived as distant, obsolete and, consequently, boring, and the knowledge (which is fragmentary and not established, but highly attractive) acquired during that 'time out of school', which is the digitized free time offered to the young student. Training teachers to use these new modalities of learning is the challenge, which both pedagogy and, therefore, the school have to deal with and win.

There are numerous pedagogues who look at new media with interest (Maragliano 2003; Rivoltella 2006), paying attention also to the world of videogames, particularly, to the so-called 'edutainment' sector. The educational, cognitive and metacognitive implications of the sophisticated technology devices involved, as well as the characteristics of creativity, socialisation, practicality and engagement, already recognised by experts in the field, qualify these devices to be considered an interesting option for playing and laboratory learning. They should be used to support the traditional didactic and educational activities in order to outline a new idea of laboratory and school. The school still appears too distant from society, which, is, instead, ruled by the audiovisual and multimedia logics. This separation is often associated with judgement of value, of what is good and what is bad, necessary to overcome all of this dichotomy. Succeeding in doing it would open new prospects of teaching, because teaching would be based on the primary need for 'letting the student be fine, feel well/comfortable' (Maragliano, 2001), for encouraging his/her interests and motivations.

Among the most delicate issues regarding the whole sector of education, attention has to be focussed on the motivation of students, in relation to learning. In fact, new media, and videogames in particular, easily succeed in motivating them because they are highly captivating. The game designer chiefly aims at involving the player, whereas teachers often overlook this aspect, focussing all their attention on education and the transmission of notions. Learning through practice (practice allowed by multimedia) permits the student to learn in an effective, personal and amusing way and the teacher to think of a course of studies, which is more appropriate, specific and satisfying. Dewey's idea of laboratory, of the continuity between school and family environment, of the relationship between student and quality of life and of the role of school in the society would be reaffirmed in all its effectiveness. Learning, in this perspective, is, then, qualified still more as 'laboratory learning', because it is incisive and significant, far apart from the mainly 
communicable-reproductive ways, open to research and focussed on the interest and motivation of the student (Maragliano, 2001). Furthermore, the school continues to stand out as a 'laboratory of democracy', of a democracy that expands, broadens and strengthens education through the use of computing, Web, and new technologies: together they promote it. In addition, this enriches the course of the student's studies further: a student, who is able to compete better with him/herself and with others. Welcoming the new communication, interaction, information and game instruments and associating them with education means not 'falling in the trap of a fruitless contrast between two life styles' (Oliverio Ferraris, 1998), which would condemn the school to a role of real marginality. New media may really represent a constitutive element of the alliance with didactics that the student claims from the school as recognition of his/her acquired rights and of the skills acquired during his/her personal record in using the technologies (Rivoltella, 2005).

Moreover, they 'qualify the curriculum, they appraise the cognitive languages and processes, above all those of childhood and adolescence, which mainly need visual concreteness, the globalism of the representation and an intense perceptive strain up to the motivation for the logical, formal and aesthetic elaboration' (Frabboni, 2006). In particular, videogames initiate some innovative learning models, which refer to metaphorical, adductive and nonlinear reasoning forms, which are unlikely to be adopted in classrooms. The line between experience and knowledge in videogames, above all in the well-devised ones, becomes finer, thus creating some immersive and experiential learning contexts. The players/students meet in a virtual and interactive laboratory, where they learn through imitation, research and practice. In this manner, videogames let us know well the real way in which children typically use them for learning; therefore, what relates to knowledge, its meaning and sense is acquired as a result of their approach to it in real contexts of use.

The use of the so-called 'Serius games' inside schools, for instance, may represent a resource for teaching, because it introduces, in a different way, a form of learning that allows the player/student to learn in a stimulating environment, through a procedure of 'attempt and mistake'. Of course, experimenting continuously means learning by doing. In this respect, the videogames become a laboratory. It is necessary to highlight that new media technologies have to be used within an integrated educational path that does not focus only on the technological aspect but which also includes the instruments of the new technologies. These new technologies may modify the practice of learning and learning well, and, therefore, they make learning become more effective and captivating. Learning through the use of new media means promoting the practice of the laboratory, in order to 're-dimension the lasting hegemony of the classroom as the unique context of capitalisation of knowledge, necessarily of transmission of reproductive knowledge, and, consequently, in order to elevate, as a sign of personal research, the quality of education. The new media outline a new idea of proxemics, new languages of space in the classroom, vis-à-vis the traditionally used classic lesson. By doing so, they cause fertile secondary effects on the group dynamics, on the relationship between teacher and students, and on the interactive and motivation communications traffic of the class "group class" (Frabboni, 2004).

In conclusion, digital media qualify as laboratory learning tools to be integrated with the most traditional ways of learning that are present in didactics, according to a perspective of integration between new instruments and the modalities of teaching-learning already present and consolidated. It is important that the student (who is engaged with very serious activities - his/her growth, adaptation, learning, solution of problems, reality trial, decoding and understanding of emotions and feelings, impulses control and the respect for rules) learns also through some 'amusing modalities', which use words, his/her hands, objects and technologies, in an osmotic relationship with others. The others may be either students or teachers. Anyway, this does not mean that the disciplines become 'recreational', but it means the beginning of introduction of the topic of study in a different manner and, at the same time, it means ensuring that information, which is acquired through the game, may be used again by students in a successive phase. In this way, the relationship between school and society, as well as the real and virtual environments, becomes increasingly closer. 'Only a structure which is lively for productive activities and which is appropriately equipped may be defined as a laboratory. A multimedia laboratory, which is more and more complete, organized and well-advanced, should certainly have a key place not only in an educational system, but in any initiative aiming at productively "engaging" the most advanced technologies' (De Bartolomeis, 2000).

\section{Conclusions}

Rethinking the concept of laboratory through the possibilities offered by new technologies, and therefore by videogames, would allow renewal of the method of 'schooling' on the basis of a pedagogical concept that still remains today unaltered in its educational validity. Furthermore, this rethinking allows overcoming of obstacles linked to organisation, spaces and the economic lack of resources, which do not allow giving life to laboratory schools organised according to the original model. What could be done, at the moment, is to satisfy the need of youngsters to feel comfortable both at home and at school. On the other hand, Dewey's lesson on continuity between the school and family environments, of the relationship between student and lifestyle, and of the school in society, can be greatly applied to this situation as well. Technologies and media represent the natural context for forming knowledge. If we do not want to fall in the trap of a sterile juxtaposition between two life styles, which risks condemning schools to a role of 'actual marginality', we must welcome the new instruments of game, of communication, of interaction and of information and bring them into teaching grounds. In addition, they must be included in the practice of teaching and 


\section{The pedagogical concept of laboratory and videogames: learning by having fun \\ Iaquinta}

learning because we cannot leave them alone anymore due to their pervasive presence. Furthermore, we must underline that educational videogames are proposed as an effective tool also in interaction between teacher and learner because they operate in an important connection between teaching and learning, knowledge and contents, as well as the individual and a group.

New technologies, and videogames in a specific way, can really change — or at least try to change - the traditional appearance of the school system through reformulation of the laboratory concept, fostering laboratory learning based on direct experience of the individual who, through, 'learning by doing', is guarantor of his/her own learning. This is a hypothesis on which it is worth continuing to reflect.

\section{References}

boyd, D.(2004). It's complicated. La vita sociale degli adolescenti sul web. Roma: Castelvecchi.

Cacioppo, M., Severino, S. (2015). La prossimità a distanza. Contributi psico-sociali per lo studio degli usi, abusi e dipendenze nel Web 2.0. Milano: Franco Angeli.

Ceccherelli, A. (2009). Nuove forme di insegnamento: i videogiochi e l'edutainment, Scuola IaD, 1.

Claro, M. (2007). Video Games And Education, OECD Background Paper for OECD-ENLACES Expert Meeting on Videogames and Education, Santiago de Chile, Chile, pp.1-21.

De Bartolomeis, F. (1978). Il sistema dei laboratori. Milano: Feltrinelli.

De Bartolomeis, F.(2000). La scuola nel nuovo sistema formativo. Bergamo: Edizioni Junior.

De Kerckhove, D.(1993). Brainframes, mente, tecnologia, mercato. Bologna: Baskerville.

Dewey, J.(1989). Scuola e Società. Firenze: La Nuova Italia.

Dewey, J.(1992). Democrazia e Educazione. Firenze: La Nuova Italia.

Fodor, J. (1999). La mente modulare. Saggio di psicologia delle facoltà. Bologna: Il Mulino.

Fodor, J. (2003). Mente e linguaggio. Roma-Bari: Laterza.

Frabboni, F. (2004). Il laboratorio. Roma-Bari: Laterza.

Frabboni, F.(2006). Didattica e apprendimento. Palermo: Sellerio.

Gardner, H.(2005). Educazione e sviluppo della mente. Intelligenze multiple e apprendimento. Trento: Erickson.

Greenfield, P.M.(1985). Mente e media. Roma: Armando.

Herz, J.C.(1998). Il popolo del joystick. Milano: Feltrinelli.

Huerre, P. (2008). Place a jeu. Jouer pour apprendre a vivre. Ris: Nathan.

Hickman L.A. (2003). Johndewey.com: cosa sarebbe piaciuto e cosa no a Dewey di Internet. In Spadafora, G. (Ed.). John Dewey. Una nuova democrazia per il XXI secolo, Roma: Anicia.

Iaquinta, T. (2005). La scuola laboratorio, Rende: Edizioni Scientifiche Calabresi.

King, L. (2002). Game on: The History and Culture of Video Games. New York, NY: Universe.

Malykhina, E. (2014). Fact or Fiction?: Video Games Are the Future of Education, Scientific American. Retrieved from http://www.scientificamerican.com/article/fact-or-fiction-video-games-are-the-future-of-education

Maragliano, R., Melai, R, Quadrio, A. (2003). Joystick. Pedagogia dei videogames. Milano: Walt Disney Company. 
Oliverio Ferraris, A.(1998). Non abdicare. In AA.VV., La realtà del virtuale. Bari: Laterza.

Perrotta, C., Featherstone, G., Aston, H. and Houghton, E. (2013). Game-based Learning: Latest Evidence and Future Directions, Slough: NFER.

Pira, F., Marrali, V. (2007). Infanzia, media e nuove tecnologie. Milano: Franco Angeli.

Rivoltella, P.C. (2005). Media Education. Fondamenti didattici e prospettive di ricerca, Brescia: La Scuola.

Rivoltella, P.C. (2006). Media Education. Modelli, esperienze, profilo disciplinare. Firenze: Carocci.

Roiazzi, C. (2003). Gioco reale, gioco virtuale e apprendimento, in "Scuola Italiana Moderna”, 10, 1 Febbraio.

Tanoni, I.,(2003). Videogiocando s'impara. Dal divertimento puro all'insegnamento-apprendimento. Trento: Erickson..

Triberti, S., Argenton, L.(2013). Psicologia dei videogiochi. Milano: Apogeo. 